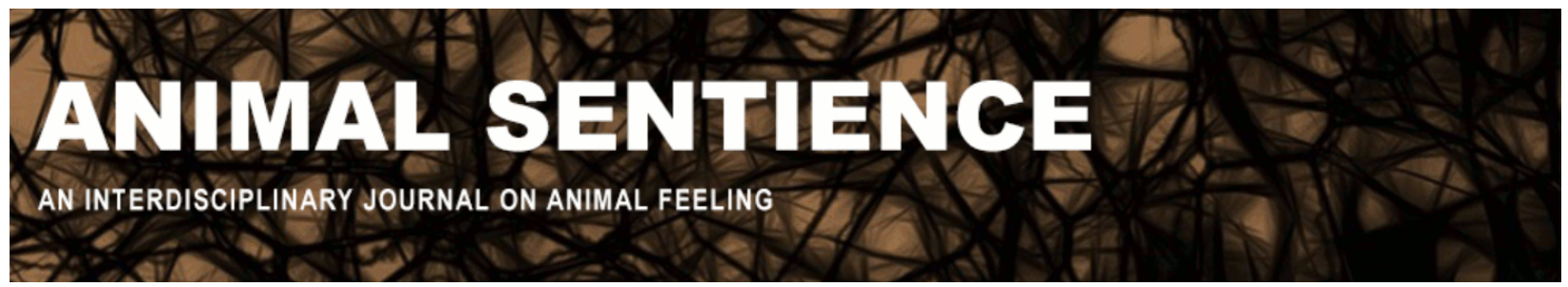

Favela, Luis H. (2019) Octopus Umwelt or Umwelten?. Animal Sentience 26(2) DOI: $10.51291 / 2377-7478.1465$

Date of submission: 2019-05-28

Date of acceptance: 2019-06-05

(c) (i)




\title{
Octopus Umwelt or Umwelten?
}

Commentary on Mather on Octopus Mind

\author{
Luis H. Favela \\ Department of Philosophy and Cognitive Sciences Program \\ University of Central Florida
}

\begin{abstract}
Even if its intelligent behaviors are the product of decentralized control systems, Mather argues that the octopus has an "Umwelt," and, thus, a mind. I argue that Umwelt does not provide a conceptual basis for understanding the octopus as having a mind. First, Umwelt does not refer only to an organism's perceptual abilities. Second, in providing evidence for decentralized control systems that underlie intelligent behaviors, Mather makes a case against an octopus Umwelt. Instead, the octopus is more akin to a collection of systems, or Umwelten, than a single system with an Umwelt.
\end{abstract}

Luis H. Favela, Assistant Professor of Philosophy and Cognitive Sciences at the University of Central Florida, does research at the intersection of philosophy and mind sciences applying complexity and dynamical systems theory to behavior, cognition, and consciousness in diverse systems at various scales. Website

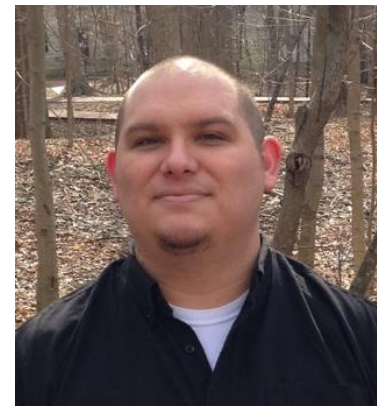

Octopuses are the "the closest we're likely to get to meeting an intelligent alien" (Godfrey-Smith, 2016, p. 200). Notwithstanding that there are those who claim they are extraterrestrial in origin (e.g., Steele et al., 2018), octopuses are just as much from Earth as birds, dolphins, elephants, and humans. Moreover, like the aforementioned terrestrial organisms, octopuses have the neurobiological equipment implicated in conscious experience (Low et al., 2012). However, unlike birds, dolphins, elephants, and humans, octopuses do not have a centralized nervous system. Yet the sophistication of their behavior seems best explained by positing a mind (cf. Dennett, 1983). Along those lines, Mather (2019) does a commendable job synthesizing various literatures to make the case that although, "the sensory Umwelt and the decentralized control systems of the octopus do not generate the same kind of mind as in vertebrates, the octopus nevertheless has one" (p. 22; italics in original).

This commentary centers on Mather's use of the concept "Umwelt." I question whether Umwelt does the work Mather needs it to do in the target article, namely, to provide a conceptual basis for understanding the way an octopus has a mind. Originating with biologist Jakob von Uexküll (1926), Umwelt refers to the subjective world of an organism, that is, "the surroundingworld of the animal" (p. 79) or "the phenomenal world or the self-world of the animal" (von Uexküll, 1934, p. 5; italics in original). Though it originated with von Uexküll, the term Umwelt has been modified and refined by others. For example, 
- "Umwelt should be understood as 'the totality of conditions contained in an entire complex of surroundings which permit a certain organism, by virtue of its specific organization, to survive"” (Gehlen, 1988, p. 71).

- "Umwelt is the semiotic world of organism. It includes all the meaningful aspects of the world for a particular organism" (Kull, 1998, p. 304).

- "Umwelt is the subjective model of the world" (Kull, 2001, p. 281; italics in original).

- "All organisms communicate by use of models (Umwelt, or self-worlds, each according to its species-specific sense organs)" (Sebeok, 2001, p. 23).

- "The Umwelt is, roughly speaking, the world as it is experienced by a particular organism" (Barrett, 2011, p. 80).

As is evident, Umwelt can be understood as being quite broad, from whatever contributes to an organism's survival (cf. Gehlen, 1988), to the semiotic relationships between an organism and world (cf. Kull, 1998). Mather utilizes Umwelt in a very specific way, namely, as referring to "the individual's perceptual and action world" (p. 2), or, its "sensory and perceptual world" (p. 10). This emphasis on perception is further evidenced by Mather's discussion of research that, she claims, made mistakes about octopuses' perceptual abilities (e.g., p. 12). In addition, grouping Umwelt with the ecological psychology concept of "affordances" further indicates a specific sense of Umwelt as referring to perceptual capacities. Finally, the target article concludes with a statement about "the sensory Umwelt" (p. 22; italics in original).

If the aim of the target article is to motivate the claim that octopuses have a mind, then focusing on their perceptual Umwelt will not necessarily suffice. This is for two reasons: First, Umwelt refers to so much more than an organism's perceptual capacities. As referenced above, Umwelt captures the subjectivity of an organism and the ways the world is meaningful for it. That is what Nagel (1974; cited in Mather, 2019, p. 2) had in mind - at least partially (e.g., limits of third-person science) - about a human not knowing what it is like to be a bat: to be a bat is to have a world so radically different from ours, radical in that bats evolved particular forms of subjectivity populated by a world full of meaningful things for them. A similar point is made by von Uexküll's (1937) discussion of a tick's Umwelt, which is comprised of three meaningful features: butyric acid (i.e., odor from mammal skin glands), $37^{\circ} \mathrm{C}$ (i.e., temperature of mammal blood), and mammalian hair (i.e., a hairless spot). Thus, in the current context, to posit that an organism has an Umwelt is to beg the question: If $X$ has an Umwelt, then $X$ has a world; and if $X$ has a world, then $X$ has a mind. Mather provides a considerable amount of empirical evidence that octopuses perceive the world and that those perceptions inform, at least in some instances, quite sophisticated actions. However, the ability to perceive and act does not necessarily equate with having an Umwelt.

The second critique I have of Mather's appeal to Umwelt is the role that concept plays in arbitrating the issue about whether an organism has a mind. In the literature cited above, Umwelt is typically used to refer to the subjective experience of an organism and the world of meaningful things for it. In other words, an organism - qua single system - has one subjective experience of the world. In that way, Umwelt is quite appropriate when used in reference to organisms with a central nervous system, specifically, organisms that have a single subjective, conscious experience of the world. Mather (2019) draws attention to the fact that "octopuses have a mixture of loci of control - sometimes the brain, sometimes along the interbrachial commissure and sometimes through the coordination of local brachial ganglia" (p. 8). Moreover, their 
"decentralized control systems" (p. 22) have not hindered but "must have contributed to the development of octopus intelligence" (p. 8). Along with other "open loop and ... not centrally monitored" systems (p. 4), it seems quite likely that octopuses do not have a single subjective, conscious experience of the world. The empirical evidence seems - to me, as a nonexpert of octopus physiology or behavior - to point to octopuses as being more akin to a distributed system, swarm, or flock (Amon \& Favela, 2019; Neemeh \& Favela, 2017) than a single, unified system. In that way, octopuses are alien in that they force us to find a new understanding of the range of possible intelligent organisms. On the one hand, octopuses are "packaged" within a single body; but on the other, many of the intelligent actions of that organism are carried out by a noncentralized system that is more akin to coordinating team members than a captain giving orders. Consequently, if an Umwelt requires a single subjective experience, and if octopuses have multiple systems - each with their own perspective - then it would be more appropriate to say that an octopus contains a collection of "Umwelten" (the plural form of Umwelt) and not a single Umwelt.

\section{References}

Amon, M. J., \& Favela, L. H. (2019). Distributed cognition criteria: Defined, operationalized, and applied to human-dog systems. Behavioural Processes, 162, 167-176.

Barrett, L. (2011). Beyond the brain: How body and environment shape animal and human minds. Princeton, NJ: Princeton University Press.

Dennett, D. C. (1983). Intentional systems in cognitive ethology: The "Panglossian paradigm" defended. Behavioral and Brain Sciences, 6(3), 343-355.

Gehlen, A. (1988). Man: His nature and place in the world (trans. C. McKillan \& K. Pillemer). New York, NY: Columbia University Press.

Godfrey-Smith, P. (2016). Other minds: The octopus, the sea, and the deep origins of consciousness. New York, NY: Farrar, Straus and Giroux.

Kull, K. (1998). On semiosis, Umwelt, and semiophere. Semiotica, 120(3/4), 299-310.

Kull, K. (2001). Umwelt. In P. Cobley (Ed.), The Routledge companion to semiotics and linguistics (p. 281). New York, NY: Routledge.

Low, P., Panksepp, J., Reiss, D., Edelman, D., Van Swinderen, B., \& Koch, C. (2012). The Cambridge declaration on consciousness. Francis Crick Memorial Conference. Cambridge, UK.

Mather, J. (2019). What is in an octopus's mind? Animal Sentience 26(1).

Neemeh, Z. A., \& Favela, L. H. (2017). Beyond distributed cognition: Towards a taxonomy of nonreductive social cognition. In G. Gunzelmann, A. Howes, T. Tenbrink, \& E. Davelaar (Eds.), Proceedings of the 39th Annual Conference of the Cognitive Science Society (pp. 2796-2801). Austin, TX: Cognitive Science Society.

Sebeok, T. A. (2001). Signs: An introduction to semiotics (2nd ed.). Toronto, Canada: University of Toronto Press.

Steele, E. J., Al-Mufti, S., Augustyn, K. A., Chandrajith, R., Coghlan, J. P., Coulson, S. G., Sudipto, G., Gillman, M., Gorczynski, R. M., Klyce, B., Louis, G., Mahanama, K., Oliver, K. R., Padron, J., Qu, J., Schuster, J. A., Smith, W. E., Snyder, D. P. ... Liu, Y. (2018). Cause of Cambrian explosion - terrestrial or cosmic? Progress in Biophysics and Molecular Biology, 136, 3-23.

von Uexküll, J. (1926). Theoretical biology. London: Kegan Paul, Trench, Trubner \& Co. Ltd.

von Uexküll, J. (1934). A stroll through the worlds of animals and men: A picture book of invisible worlds. In C. H. Schiller (Eds.), Instinctive behavior: The development of a modern concept (pp. 5-80). New York, NY: International Universities Press, Inc. 